\title{
The Compressive Strength of Concrete Containing Eggshell Powder and Palm Oil Fuel Ash Cured in Tap Water and River Water
}

\author{
Mazizah Ezdiani Mohamad ${ }^{1}$, Ali A. Mahmood ${ }^{2}$, EH Cheng Chen ${ }^{3}$ \\ (Dept. of Civil Engineering, University College of Technology Sarawak, 868 Persiaran Brooke, 96000 Sibu, \\ Sarawak, Malaysia)
}

\begin{abstract}
Cement production is a major environmental problem that causes the release of carbon dioxide into the atmosphere. This study attempts to sustainably use palm oil fuel ash (POFA) and eggshell powder (ESP) as partial replacements for Ordinary Portland cement (OPC) in concrete production. POFA and ESP are two wastes that need to be managed to reduce their detrimental environmental effects. As such compressive and slump tests were conducted on POFA-ESP-OPC concrete mixtures by replacing $10 \%$ of OPC with POFA-ESP. Two mediums of curing were used: tap water and river water. It was found that the compressive strength and slump resistance of these mixtures were within the ranges typically encountered in regular concrete mixtures indicating the viability of this procedure employed for structural applications.
\end{abstract}

Key words: Egg shell powder (ESP); Palm Oil Fuel Ash (POFA); Compressive strength; Tap water; River Water

\section{Introduction}

The emission of carbon dioxide due to the production of cement causes environmental pollution and global warming. The production of 1 tonne of cement manufacturing processes approximately 900 $\mathrm{kg}$ of carbon dioxide (CO2) is emitted [1]. Therefore the need rise more than ever before to find alternative for cement in concrete production. Biofiller wastes such as eggshell powder (ESP) and palm oil fuel ash (POFA) are two such alternatives and they are abundant in Malaysia in general and in the state of Sarawak in particular. Both wastes are a cause of environmental hazard that affects water resources and the living environment. Consequently a method was devised to use these wastes sustainably in construction applications in the making of concrete [2-3]. Previous studies have shown that ESP was able to replace up to $75 \%$ of commercial calcium carbonate $(\mathrm{CaCO} 3)$ as a partial replacement of cement in concrete composites [3]. Also studies of ESP have shown that it performed better than all other types of $\mathrm{CaCO} 3$ with different particle sizes.

On the other hand, POFA contains $40 \%$ silicon dioxide, which is an essential strength component. POFA was previously shown to be a viable cement replacement enabling longer initial and final setting times [4]. Sata et al. [5] reported that replacing cement with up to $30 \%$ POFA produced high strength concrete of about $86 \mathrm{MPa}$.

Due to scarcity of clean water in many part of Sarawak, there is a need to look for alternative water sources for curing concrete. One such alternative is river water. As such, this study looks into investigating the potential suitability of ESP-POFA as sustainable materials in partially replacing concrete cement. The experiments conducted were: compressive strength and slump test. Curing of these mixtures was done in tap and river waters to further ascertain the viability of using alternative water sources in the curing of concrete.

\section{Experimental Program}

\subsection{Material and Mix Proportion}

ESP and POFA were grinded and sieved using a $75 \mu \mathrm{m}$ sieve for ESP and a $45 \mu \mathrm{m}$ sieve for POFA. The ESP and POFA were used as $10 \%$ cement replacement by weight. Figure 1(a) and 1(b) shows the ESP and POFA and Figure 2 shows the specimen dimensions. The cement used in this study was Ordinary Portland (OPC) Type $1.10 \mathrm{~mm}$ well graded 
crushed granite and locally available river sand were used for the coarse and fine aggregates, respectively. The concrete mixing procedure consisted of various ratios of ESP and POFA at 10\% cement replacement, OPC, fine and coarse aggregates. Clean tap water was used as the mixing medium to achieve reasonable workability. Concrete strength was designed to achieve compressive strength of $30 \mathrm{~N} / \mathrm{mm} 2$ at 28 days. Water to cement ratio was fixed at 0.54 . The mix proportions of ESP: POFA as $10 \%$ cement replacements are as follows: (i) $0 \%$ (control), (ii) $10 \%$ ESP:0\% POFA, (iii) 8\% ESP:2\% POFA, (iv) 6\% ESP:4\% POFA, (v) 4\% ESP:6\% POFA, (vi) $8 \%$ ESP:2\% POFA and (vii) 10\% ESP:0\% POFA. Table 1 shows these mix proportions. Three specimens were casted for each mixture of concrete with two batches (tap and river water) giving a total of forty-two (42) specimens. Subsequently each one batch was cured in tap water and the other in river water.

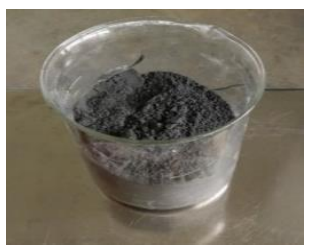

(a)

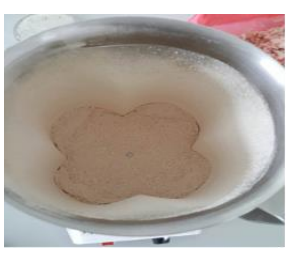

(b)

Figure 1.0: Palm Oil Fuel Ash (POFA)

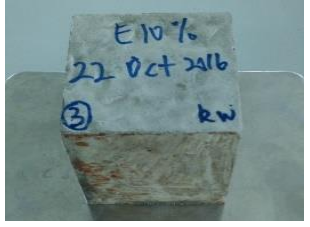

Figure 2.0: Specimen dimension

Table 1.0: Mix Proportions of specimens

\begin{tabular}{|c|c|c|c|c|c|c|}
\hline 肴总 & 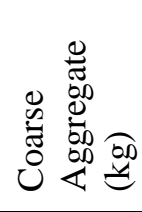 & 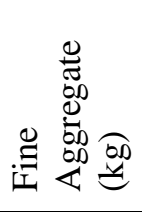 & 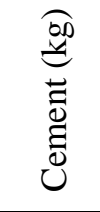 & 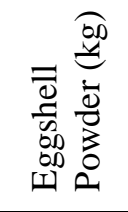 & 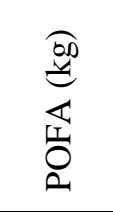 & 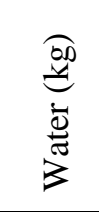 \\
\hline Normal Mix & 7.318 & 3.769 & 3.082 & - & - & 1.538 \\
\hline E10\% & 7.318 & 3.769 & 2.774 & 0.3082 & - & 1.538 \\
\hline $\mathrm{E} 8 \%, \mathrm{P} 2 \%$ & 7.318 & 3.769 & 2.774 & 0.247 & 0.062 & 1.538 \\
\hline E6\%,P4\% & 7.318 & 3.769 & 2.774 & 0.185 & 0.123 & 1.538 \\
\hline $\mathrm{E} 4 \%, \mathrm{P} 6 \%$ & 7.318 & 3.769 & 2.774 & 0.123 & 0.185 & 1.538 \\
\hline $\mathrm{E} 2 \%, \mathrm{P} 8 \%$ & 7.318 & 3.769 & 2.774 & 0.062 & 0.247 & 1.538 \\
\hline P10\% & 7.318 & 3.769 & 2.774 & - & 0.3082 & 1.538 \\
\hline
\end{tabular}

\subsection{Curing Method}

Two different methods of curing were used to cure the concrete specimens in this study; curing in tap water and curing in river water. The river water used was obtained from the Rejang river in Sibu, Sarawak. Figure 3 shows the specimens under curing in both types of water.
The river water was subjected to the chemical oxygen demand (COD) test to measure the amount of organic compounds present. Furthermore, river samples were tested for their $\mathrm{pH}$ values before and after the curing process. 


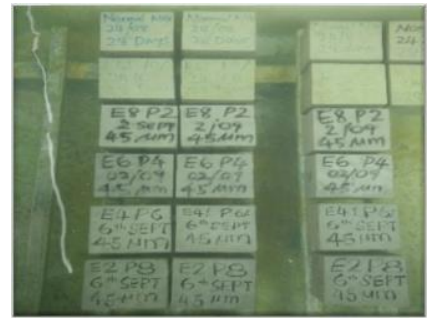

(a)

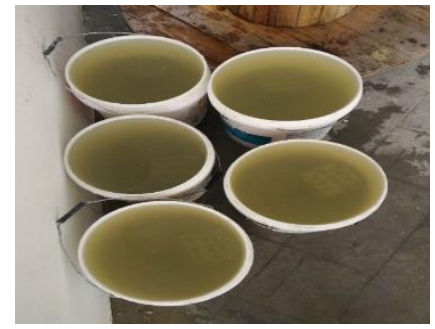

(b)

Figure 3.0: Curing Method: (a) concrete cured in tap water and (b) concrete cured river water

\subsection{Slump Test}

The concrete mixtures were tested for workability using the slump cone test. The main purpose of the test is to determine the effect of adding ESP and POFA on concrete workability. The testing procedure followed the method given in BS EN 12390-2 [6].

\subsection{Compressive Strength Test}

Eighteen (18) cubes of $100 \times 100 \times 100 \mathrm{~mm}$ were used to determine the compressive strength. The compressive strength mix design was $30 \mathrm{~N} / \mathrm{mm}^{2}$ for each mixture after 28 days of curing. The compression test was carried out using ADR Auto V2 $3000 \mathrm{kN}$ compression machine as shown in Figure 4. The pace rate for the compression test applied was 7.0 $\mathrm{kN} / \mathrm{s}$. The loading pace was constantly applied until the specimens visibly failed. The compressive strength for each proportion was determined after 28 days of curing in tap water and river water. The procedures used in carrying out each test were in accordance with BS EN 12390-3 [6].

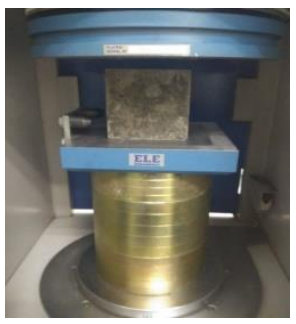

Figure 4.0: Compression Test

\section{Results And Discussion}

\subsection{Concrete Workability}

The concrete slump relationship for all mixtures including control (normal concrete) is shown in Figure 5. It is shown that the ESP-POFA concrete marginally altered the workability of fresh concrete, for all the mixtures considered.

It was found that adding ESP only in concrete mixture increased its workability. In particular, adding POFA with and without ESP in concrete mixture reduced its workability and increased the concrete resistance to flow. This can be seen in Figure
5 where a descending pattern was observed after the highest workability at 10\%ESP: 0\%POFA. This decline in workability, when adding POFA, might be due to the water absorption potential of POFA. The combined ESP-POFA in the mixture show the lowest slump at $80 \mathrm{~mm}\left(1^{\text {st }}\right.$ batch $)$ and $80.5 \mathrm{~mm}\left(2^{\text {nd }}\right.$ batch $)$. All slump values found experimentally fall within the $50-100 \mathrm{~mm}$ range suggesting that these values are for medium workability values for normal reinforced mixed concrete [7]. This suggests that using POFAESP to partially replace OPC is viable and applicable in concrete mixes. This further suggests that the curing procedure using river water did not have an adverse effect on the workability of these mixtures. 


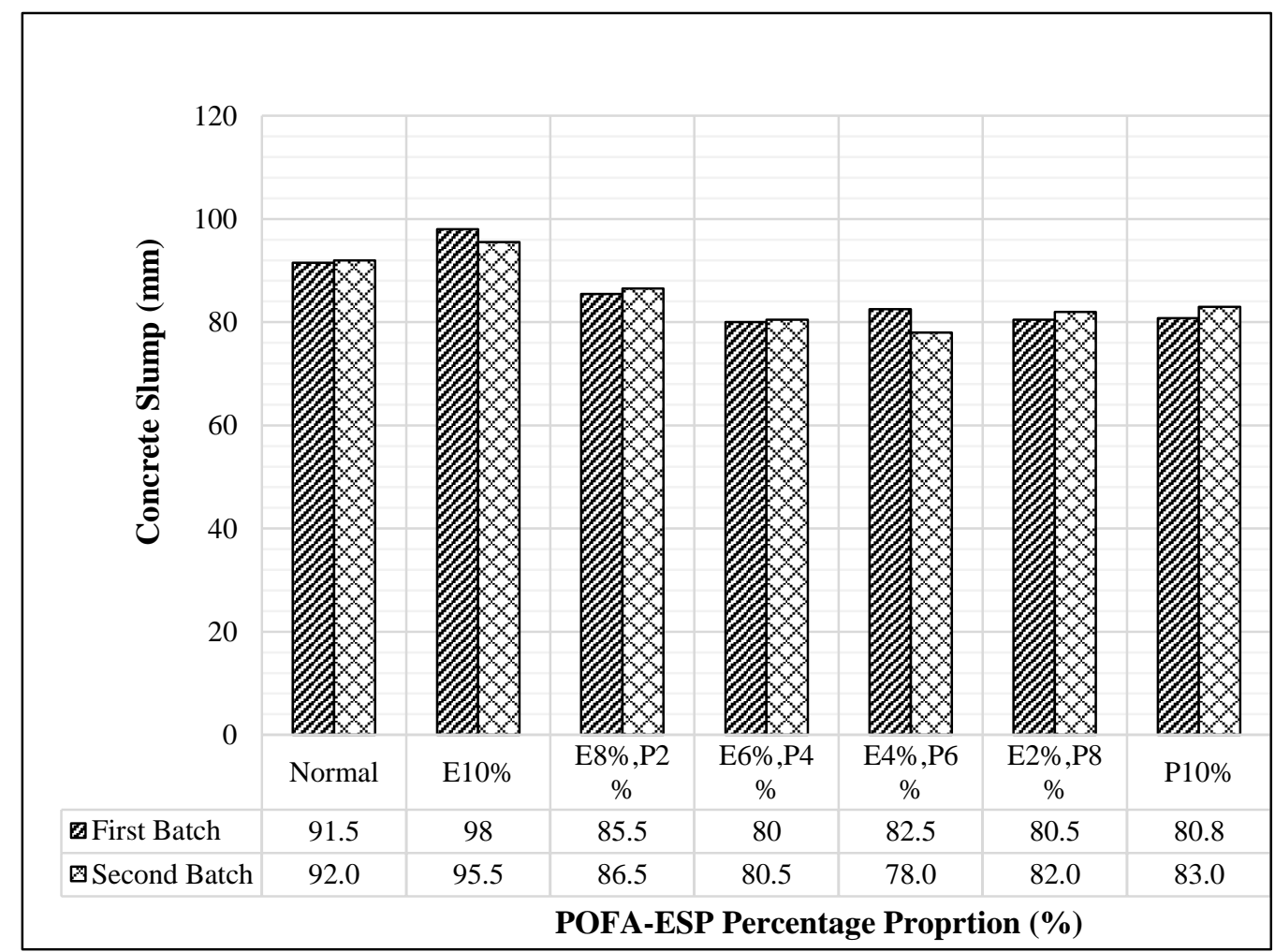

Figure 5.0: Concrete slump for ESP-POFA mixtures

\subsection{Compressive Strength}

Results of the compressive strength after 28 days of curing for all mixtures, including control, are shown in Table 2. It is seen that the compressive strength for all mixtures achieved the targeted design strength of $30 \mathrm{~N} / \mathrm{mm}^{2}$ at 28 days.

It was seen that the concrete mixture with $8 \%$ ESP-2\% POFA cement replacement achieved the highest compressive strength, when cured in tap water, in comparison to all other mixtures, including control. As for river water cured specimens, it was seen that the normal mixture had the highest compressive strength followed by the mixture with $4 \%$ ESP and 6\% POFA. Abd elaty [8] who did an extensive research study on many types of concrete mixtures from the literature reported values for concrete strength after 28 days of curing from Lea's Chemistry of Cement and Concrete [9]. The values range from $36.1-56.5 \mathrm{~N} / \mathrm{mm}^{2}$. Most of the values found in this research and shown in Table 2 fall within this range, indicating that using POFA and ESP as partial replacements for concrete cement is viable and strength-wise feasible. Furthermore, this shows that curing these concrete cubes in river water did not alter their strength properties, in comparison to regular tap water, as the range of strength was within acceptable limits for regular concrete [9]. 
Maziah, Ali \& Chen/ Journal of Engineering and Science Research,3(1) 2019, Pages:24-29

Table 2.0: Compressive strength at 28 days cured in tap water

\begin{tabular}{|c|c|c|}
\hline \multirow{2}{*}{ Concrete Specimens } & \multicolumn{2}{|c|}{ Compressive strength $\left(\mathrm{N} / \mathrm{mm}^{2}\right)$} \\
\cline { 2 - 3 } & Tap water & River water \\
\hline Normal & 41.83 & 41.47 \\
\hline ESP10\% & 39.67 & 34.17 \\
\hline 8\%ESP:2\%POFA & 44.63 & 38.40 \\
\hline 6\%ESP:4\%POFA & 35.43 & 35.90 \\
\hline 4\%ESP:6\%POFA & 33.20 & 39.73 \\
\hline 2\%ESP:8\%POFA & 35.43 & 37.90 \\
\hline 10\%POFA & 40.93 & 36.03 \\
\hline
\end{tabular}

\subsection{Water quality}

Figure 6 shows the $\mathrm{pH}$ values of different water sources used in the curing process. The tap water contains no impurities and organic content and shows a $\mathrm{pH}$ value at 6.76. Meanwhile, the $\mathrm{pH}$ of river water increased to become more alkaline, after curing, to 10.34 up from 7.83. According to McNally et. al. [10], the calcium carbonate $\left(\mathrm{CaCO}_{3}\right)$ and other bicarbonates increases the alkalinity of water [10].
The $\mathrm{pH}$ value river water after curing concrete for 28 days increased due, possibly, to the calcium carbonate contained in ESP.

Table 3 shows the COD of river water before curing is within 13-128 mg/L. River water contains high dissolved oxygen which is capable of changing the water quality and affecting the compressive strength. After 28 days curing, the river water COD increased to $128 \mathrm{mg} / \mathrm{L}$.

Table 3.0: COD of river water

\begin{tabular}{|c|c|c|}
\hline \multirow{2}{*}{ Parameters } & \multicolumn{2}{|c|}{ Water samples } \\
\cline { 2 - 3 } & $\begin{array}{c}\text { Rajang river before curing } \\
\text { process (A) }\end{array}$ & $\begin{array}{c}\text { Rajang river after curing } \\
\text { process (B) }\end{array}$ \\
\hline COD ULR (mg/L) & 12.7 & 9.1 \\
\hline COD LR (mg/L) & 44 & 47 \\
\hline COD HR(mg/L) & 13 & 128 \\
\hline
\end{tabular}

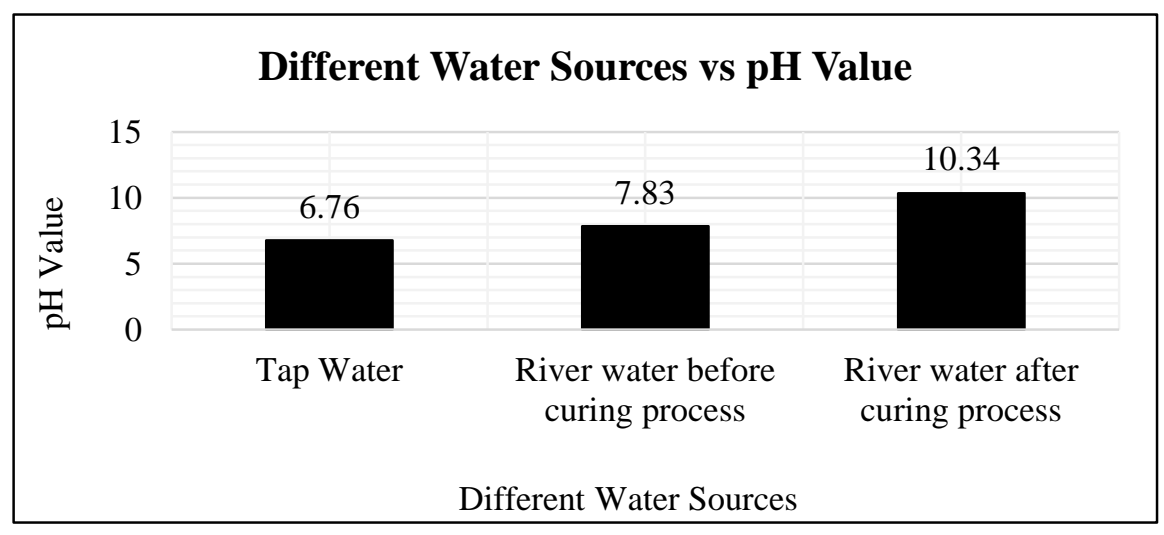

Figure 6.0: Different water sources against pH Value 


\section{Conclusion}

Workability, compressive strength and water quality testing have been carried out on several ESP:POFA-concrete mix proportions of . The aim was to replace $10 \%$ of cement by weight and investigate experimentally the newly-formed matrices.

Based on the test results, the following conclusions can be made:

(i) The workability of fresh concrete is found to be inversely proportional to the ESP ratio.

(ii) The optimum mixture proportion for strength at 28 days of curing in river water is 4\% ESP: $6 \%$ POFA.

(iii) The optimum mixture proportion for strength at 28 days of curing in tap water is 8\% ESP: $2 \%$ POFA.

(iv) Compressive strength and slump values of POFA-ESP-OPC concrete mixtures fall within the range reported in the literature for normal concrete mixtures at 28 days. This suggests the viability of using this sustainable approach in construction and further verifying the applicability of the river water curing procedure.

(v) $\quad \mathrm{pH}$ for river water increased to 10.34 after curing possibly due to the calcium carbonate contained in the ESP and its COD increased to $128 \mathrm{mg} / \mathrm{L}$.

\section{Acknowledgements}

This article was supported by University College of Technology Sarawak (UCTS) Research Grant (UCTS/RESEARCH/1/2016/06).

\section{References:}

[1] Dhanalakshmi, M., 2015. A Comparative Study on Egg Shell Concrete with Partial Replacement of Cement by Fly Ash. , 4(05), pp.1532-1538.

[2] P. Pliya and D. Cree, "Limestone derived eggshell powder as a replacement in Portland cement mortar," Constr. Build. Mater., vol. 95, pp. 1-9, 2015.

[3] P. Toro, R. Quijada, M. Yazdani-Pedram, and J. L. Arias,
"Eggshell, a new bio-filler for polypropylene composites," Mater. Lett., vol. 61, no. 22, pp. 4347-4350, 2007.

[4] C. Engineering, "Utilization of palm oil fuel ash in concrete : A review," no. June, 2011.

[5] V. Sata, C. Jaturapitakkul, and K. Kiattikomol, "Influence of pozzolan from various by-product materials on mechanical properties of high-strength concrete," Constr. Build. Mater., vol. 21, no. 7, pp. 1589-1598, Jul. 2007.

[6] BS, "EN 1239. Testing Hardened Concrete. Part 2: C Testing Fresh Concrete Slump test.," 2009.

[7] Arthur Lyons (2007). Materials for architects and builders. Butterworth-Heinemann

[8] M. A. Abd elaty. Compressive strength prediction of Portland cement concrete with age using a new model. HBRC Journal (2014) 10, 145-155

[9] P.C. Hewlett, Lea's Chemistry of Cement and Concrete, Elsevier Butterworth-Heinemann, New York, 2005 (Chapter 6).

[10] A. J. McNally, W. H., \& Mehta, "Sediment Transport and Deposition in Estuaries Estuaries," Encycl. Life Support Systesm Coast. Zo. Estuaries., 2004. 